\title{
Nanoparticles of metal and metal oxides: some peculiar synthesis methods, size and shape control, application to catalysts preparation
}

François Bozon-Verduraz, ${ }^{*}$ Fernand Fiévet, Jean-Yves Piquemal, Roberta Brayner, Kaoutar El Kabouss, and Yaghoub Soumare ITODYS UMR CNRS 7086, Universitè Paris Diderot, 15 rue Jean de Baïf, 75205 Paris cedex 13

\author{
Guillaume Viau
}

Laboratoire de Physique et Chimie des Nano-Objets, INSA de Toulouse, 31077 Toulouse cedex 4

Georges Shafeev

Wave Research Center, General Physics Institute of the Russian Academy of Sciences, Moscow, Russian Federation

(Received on 1 July, 2008)

\begin{abstract}
One step (direct) and multisteps synthesis methods of metal and oxide nanoparticles are presented including both bottom-up and top-down procedures. Chemical methods involving the polyol process allows to get either isotropic or anisotropic nanoparticles. Nanowires, nanorods and dumbells can be generated either by heterogeneous nucleation or by using a template (mesoporous silica). Top-down procedures are illustrated by laser irradiation of immersed bulk targets (Ag, $\mathrm{Au}$ ) which generates self-organized nanostructures or colloidal solutions. Laser irradiation of these colloidal solutions modifies the size distribution and the shape of nanoparticles. Bimetallic nanoparticles are generated from mixtures of monometallic colloidal solutions. Surface-mediated methods involving a host support and an invited phase are also presented. They lead to the formation of metal or oxide clusters and nanoparticles. The speciation of these entities is correlated with the observed catalytic performances.
\end{abstract}

Keywords: polyol process, laser ablation, anisotropy, cobalt, palladium, ruthenium, silver, gold.

\section{INTRODUCTION}

Numerous papers and books have been dedicated to the synthesis of nanomaterials and nanostructures [1,2]. The aim of the present paper is (i) to focus on some peculiar synthesis methods developed in our laboratories, pertaining either to chemical (bottom up) or to physical (top down) methods, (ii) to present their ability to control size and shape; (iii) to show some applications related to catalysts preparation. For conciseness, the cited references are not exhaustive and have been mainly chosen to illustrate the synthesis methods presented below, dedicated to the genesis of metal and oxide nanoparticles. Most examples will concern the so-called "zero-dimensional nanostructures", that are nanoparticles in the general sense (with no peculiar direction of anisotropic growth) and "one-dimensional nanostructures" called nanowires and nanorods [1,2]. Indeed, these anisotropic structures are highly interesting since they exhibit properties which differ markedly from those of isotropic nanoparticles. For example, metallic silver nanowires display two plasmon resonances which correspond to longitudinal and transverse collective electron oscillations whereas silver nanospheres only display one resonance. Moreover, the maximum of the longitudinal oscillation depends on the aspect ratio (length/width ratio) of the particle. In the same manner, it is possible to considerably increase the coercive field of ferromagnetic particles, by adding a contribution related to the shape anisotropy [3], which is of outmost importance in the design of magnets. We shall present two classes of procedures: one step (direct) and multisteps. In the latter we focus on supported nanoparticles obtained by either (i) the precursor fixation (anchoring, impregnation, exchange) on the host

${ }^{*}$ Electronic address: bozonver@univ-paris-diderot.fr support, followed by its transformation into the invited phase (oxide or metal) or (ii) the creation of the invited phase in solution before its fixation (immobilization) on the support. These methods are summarized in scheme 1. For conciseness, the photodeposition (photo-assisted reduction), which concerns only semiconductors, will not be treated. Collodal oxide solutions (sols) can be obtained by hydrolysis of a precursor in solution - polyol process (route 1) or another one (route 2) - or by laser irradiation of a target immersed in an appropriate solvent (route 3). A supported oxide can be designed via either (i) impregnation of the support by a colloidal solution (route 4) or (ii) calcination of the supported precursor (route 5) obtained from various interaction modes between the support and the precursor solution. Colloidal metal solutions may be obtained by reduction of the precursor in solution via the polyol process (route 6) or by laser irradiation of an immersed metal target (route 7). Supported metals are designed through several pathways: (i) reduction of supported oxides (route 8 ); (ii) reduction of the precursor via the polyol process in a suspension containing the support (route 9); (iii) impregnation of the support by a colloidal metal solution (route 10). Finally self-organized nanostructures may be designed by laser irradiation of an immersed target (route 11). The results presented in the present work are limited to routes $2,5,6,7,11$.

\section{EXPERIMENTAL SECTION}

\subsection{Preparation methods}

Detailed information concerning the routes presented in scheme 1 are available in the references cited in sections 3 and 4 . 


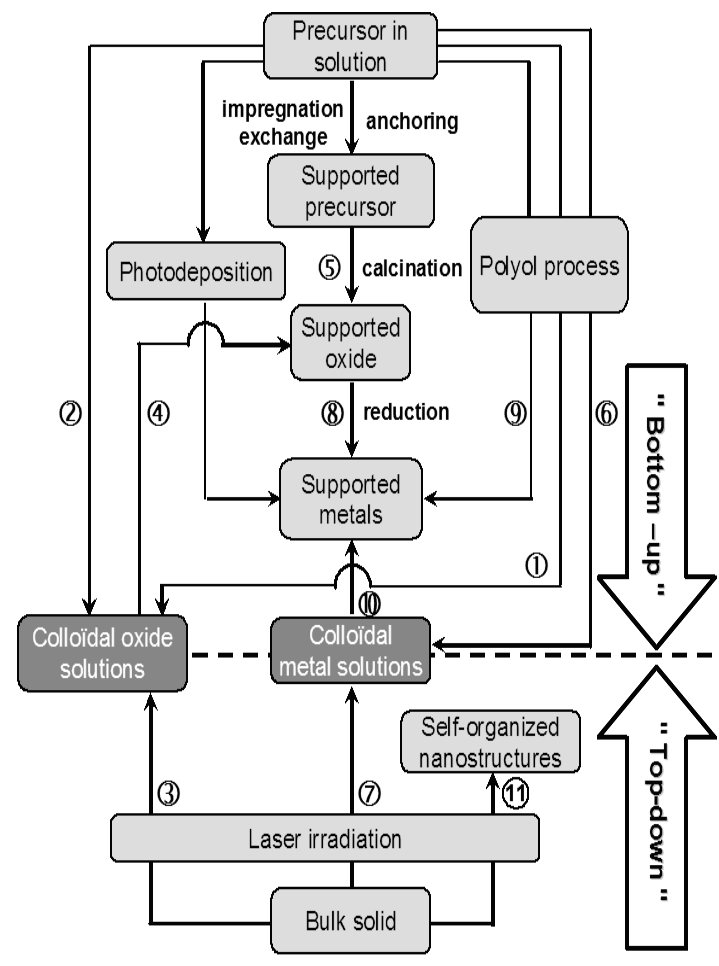

Scheme 1. Flow-chart for the preparation of oxide and metal nanoparticles

\subsection{Characterization techniques}

X-Ray diffraction patterns were obtained with a Panalytical X'Pert Pro diffractometer equipped with an $X^{\prime}$ 'celerator detector, generally in the $10^{\circ}-110^{\circ}(2 \theta)$ range using Co K radiation $(\lambda=1.7889 \AA)$. The data were collected at room temperature with a step of 0.017 degrees $(2 \theta)$ and a time by step equal to $25 \mathrm{~s}$. Transmission electron microscopy (TEM) observations were carried out with a Jeol CXII microscope operating at $100 \mathrm{kV}$. The sample powder was dispersed in ethanol, one drop of the suspension was deposited on the carbon membrane of the microscope grid and the solvent was evaporated at room temperature. High resolution transmission electron microscopy (HRTEM) was performed with a Jeol JEM 2010F UHR operating at $200 \mathrm{kV}$. UV-visible-NIR spectra by transmission and diffuse reflectance were recorded at room temperature between 190 and $2500 \mathrm{~nm}$ on a Varian Cary 5E spectrometer equipped with a double monochromator. The integrating sphere used for diffuse reflectance measurements was coated with polytetrafluoroethylene (PTFE) and PTFE was used as a reference. Laser ablation in the nanosecond range involved a $\mathrm{Cu}$ vapour laser $(578 \mathrm{~nm})$ and a $\mathrm{Nd}$ : YAG (1064 nm). The morphology of the target was characterized by an Atomic Force Microscope (AFM) operating in the tapping mode. The exposed Ag plate was characterized by specular reflectivity using an Ocean optics spectrometer in the $20-650 \mathrm{~nm}$ range. DC magnetic susceptibility was measured on a SQUID magnetometer in the $5-300 \mathrm{~K}$ range under a magnetic field of 200 Oe.

\section{DIRECT METHODS FOR THE PREPARATION OF NANOPARTICLES}

\subsection{Reduction or hydrolysis in polyols: a versatile method to prepare fine metal or oxide particles}

The polyol process, developed in our laboratory, is a soft chemistry ("chimie douce") method which allows to prepare oxide or metal nanoparticles with controlled size and shape $[4,5]$. The polyol acts as a solvent for the metal precursors (high permittivity), a growth medium and a complexing agent in some cases. In addition, it is also a mild reducing agent. This process permits to tune the particle size, shape, composition and structure of particles via the control of the nucleation and growth steps and, in the recent years, it has called a growing attention. With the help of various additives, surfactants (e.g. polyvinylpyrrolidone) and microwave heating, various types of nanoparticles have been synthetized [6-40]. Metals (Ni [6, 7], Co [8,9], Cu [10], Pd [11], Ag [12-14], Pt [15-17], $\mathrm{Au},[18,19])$, alloys [9, 19-25], oxides $\left(\mathrm{MgO}, \mathrm{TiO}_{2}, \mathrm{ZnO}\right.$, $\mathrm{SnO}_{2}, \mathrm{Gd}_{2} \mathrm{O}_{3}, \mathrm{Fe}$ oxides and ferrites, hydroxyapatite[26-35], metal-polymer nanocomposites [36], supported metal catalysts [37-40], have been designed.

\subsubsection{Isotropic particles}

Briefly, the nucleation and growth steps are controlled by the temperature, the composition of the reacting medium (basicity, hydrolysis ratio), the steric (polyol, PVP) or electrostatic (adsorption of acetate ions) stabilization [4,5].

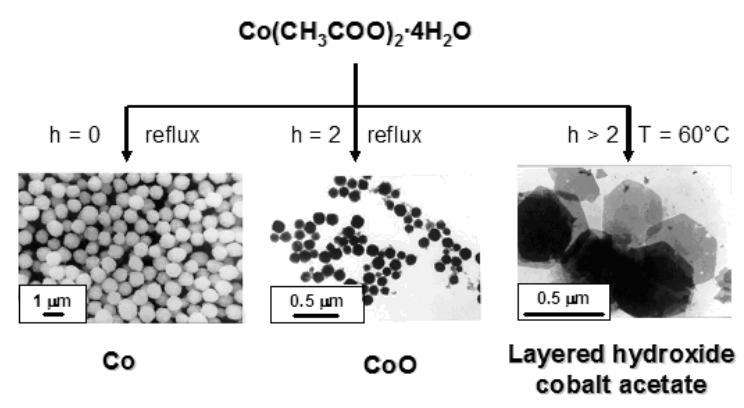

FIG. 1: The polyol process : a versatile method for the production of oxide or metal nanoparticles. After ref. [4]

A very important parameter is the hydrolysis ratio, defined as $\mathrm{h}=\mathrm{n}_{\mathrm{H} 2 \mathrm{O}} / \mathrm{n}_{\text {metal }}(\mathrm{mol} / \mathrm{mol})$. Varying $\mathrm{h}$ allows to prepare either metal, (oxy)hydroxide or oxide nanoparticles as indicated in Figure 1 [4,5]. Indeed, for cobalt - based systems, with $\mathrm{h}=0$ (water coming from the metal precursor is continuously distilled off) leads to sub-micronic (about $0.1 \mu \mathrm{m}$ ) metal nanoparticles, whereas with $\mathrm{h} \neq 0$, either oxide or layered cobalt hydroxyacetate are generated.

\subsubsection{Control of the particle shape}

Anisotropic metal nanoparticles are extensively studied because of their unique properties (optical, magnetic) com- 
pared to their isotropic counterparts. For example the plasmon spectrum of spherical $\mathrm{Ag}$ and $\mathrm{Au}$ particles presents one maximum in the visible range whereas shape-anisotropy is able to induce a second maximum at higher wavelength [41]. On the other hand shape-anisotropy may reinforce the values of the coercitive field, allowing to improve significantly the hardness of magnets. Several methods based on the use of solid templates have been described for the preparation of anisotropic particles [1, 2]. For instance, anodic aluminium oxide, nuclear-etched polycarbonate membranes or mesoporous silicas have been largely used. Following this approach, we have developed a very fast and direct procedure for the obtention of metallic silver nanowires embedded in a SBA-15-type hexagonal mesoporous silica (see Figure 2a and 2b) [18]. Another strategy consisted in the use of the system $\mathrm{Ag}\left(\mathrm{NO}_{3}\right) / \mathrm{C}_{12} \mathrm{H}_{25} \mathrm{SH} /$ polyoltoluene/ $\mathrm{CH}_{3} \mathrm{COONa}-\mathrm{CH}_{3} \mathrm{COOH}$. The formation of silver nanowires (see Figure 2c) was explained by the in situ precipitation of a lamellar silver thiolate, $\operatorname{Ag}\left(\mathrm{SC}_{12} \mathrm{H}_{25}\right)$, acting as a template for the 1D coalescence of isotropic $\mathrm{Ag}$ nanoparticles. Heterogeneous nucleation has also proved to be an efficient method for the control of the particle growth. Using Ruthenium as a seed ( $\mathrm{Ru}$ is more easily reducible than cobalt or nickel), allows to get nickel-cobalt ( figure 3a) or cobalt (figure $3 b$ ) nanowires $[16,17]$. Note that the addition of a heterogeneous nucleating agent is critical since without $\mathrm{Ru}$, only isotropic polycrystalline sub-micronic particles are obtained (see Figure $3 \mathrm{c}$ ).

\subsection{Niobia sols prepared by digestion in hydrazine and redispersion in ethanol}

Niobia, $\mathrm{Nb}_{2} \mathrm{O}_{5}$, is a wide gap semiconductor $(\mathrm{Eg}=3.4 \mathrm{eV})$. Niobia sols prepared by digestion in hydrazine and redispersion in ethanol show a marked quantum size effect $(\mathrm{Eg}=4.2$ eV) (Figure 4) [42]. The band gap width has been calculated according to a method previously developed [43]. Briefly the band gap energy increases when the number of interconnected metal-oxygen polyedra decreases. In niobia sols, the particle size is only $4.5 \mathrm{~nm}$ instead of $40 \mathrm{~nm}$ in bulk niobia. Hence, the pronounced shift towards lower wavelength (higher energy ) observed in the former case is accounted for by the lowest number of interconnected $\mathrm{NbOx}$ polyedra.

\subsection{Laser irradiation of immersed solid targets or colloidal solutions}

\subsubsection{Laser ablation of solid metal target}

Laser ablation of bulk metals immersed in liquid media (water or non-aqueous solvents) generates collodal solutions [44-46]. The nanoparticle size depends on both the laser fluence and the nature of the liquid. The thickness of the molten layer on the target increases with the laser fluence. The molten layer is transformed into nanoparticles under recoil pressure of the vapor of the surrounding liquid. Thicker melt layer is dispersed into larger nanoparticles. As the vapor pressure depends on the nature of the liquid ( higher boiling

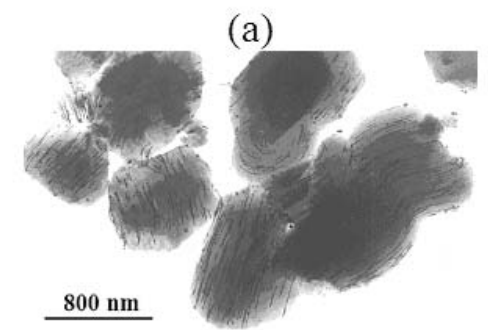

(b)

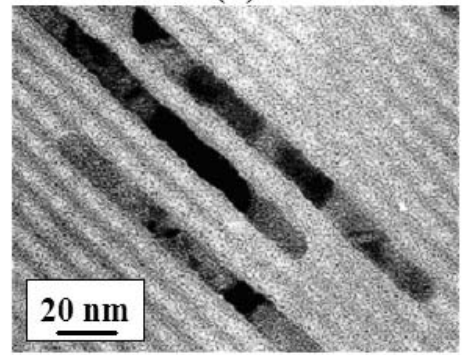

(c)

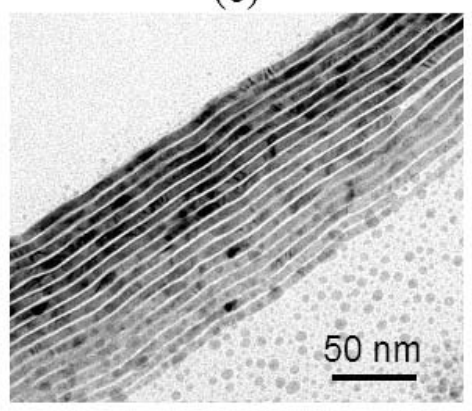

FIG. 2: Formation of Ag nanowires in hexagonal mesoporous silica $(\mathrm{a}, \mathrm{b})$ and using silver thiolate precursors (c). After ref [18, 20]

temperature means lower vapor pressure at the same temperature), the efficiency of melt dispersion depends on the nature of the liquid. In addition the plasmon frequency strongly depends on the particle shape. Whereas spherical particles show one symmetrical band, ellipsoidal ones or nanorods exhibit two plasmon oscillations, depending on the relative directions of the incident light (transverse and longitudinal) and of the particle axis. It gives rise to a supplementary absorption at lower energy (higher wavelength), leading to an assymetric band or even to the appearance of a separate longitudinal peak [18]. In the present work, elongated Au nanoparticles have been obtained and characterized by their plasmon frequencies.

\subsubsection{Laser irradiation of colloidal solutions}

Laser irradiation of monometallic collodal solutions modifies the size distribution and shape of nanoparticles. $\mathrm{Au}$ nanorods synthetized by laser ablation of an immersed gold target may be fragmented by tuning the wavelength of the laser radiation [46]. Similar results have been obtained on goldened NiCo nanorods prepared by electroless deposition of $\mathrm{Au}$ on NiCo nanorods obtained by heterogeneous nucleation (section 3.1.2.). Exposure of these nanorods to the radiation of a Nd/YAG laser (fig.5) leads to (i) an increase of 
(a)

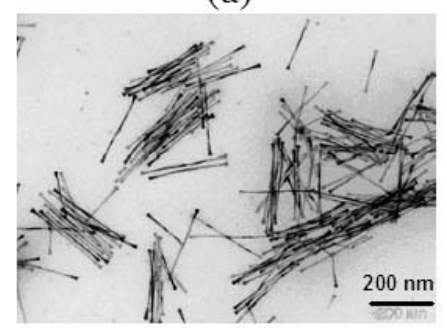

(b)

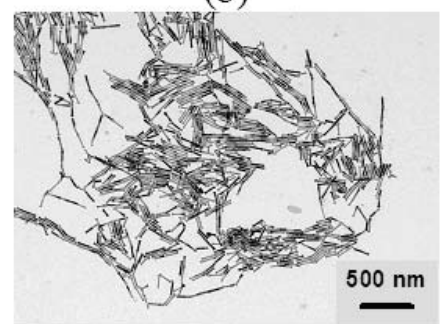

(c)

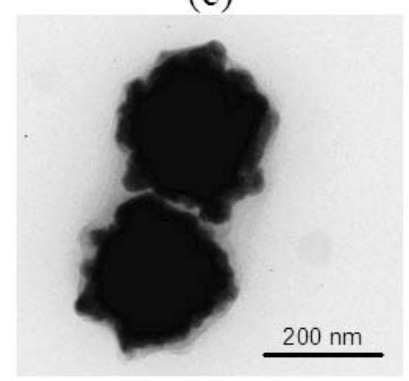

FIG. 3: Obtention of metallic (a) $\mathrm{Co}_{80} \mathrm{Ni}_{20}$ nanowires and (b) Co nanorods by using $\mathrm{Ru}$ seeds. (c) Isotropic particles are generated without $\mathrm{Ru}$ seeds

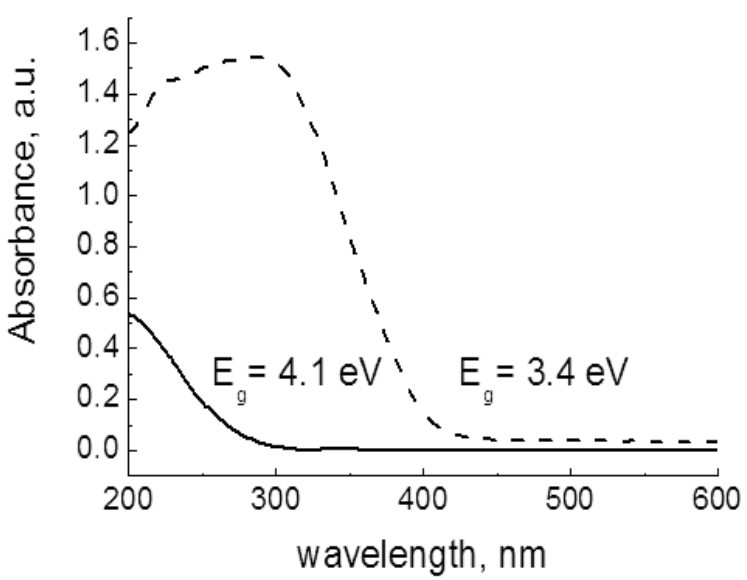

FIG. 4: UV-Visible spectra of bulk niobia (diffuse reflectance, dashed line) and niobia sol (transmission spectrum, solid line). After ref [42]

absorbance in the $500-560 \mathrm{~nm}$ range, indicating an increase of concentration of spherical nanoparticles upon fragmentation, (ii) a gradual decrease of absorbance in the IR region , attesting a decrease of concentration of elongated AuNiCo nanorods.

In addition, $\mathrm{Ag}$-Au alloys may be obtained by irradiation

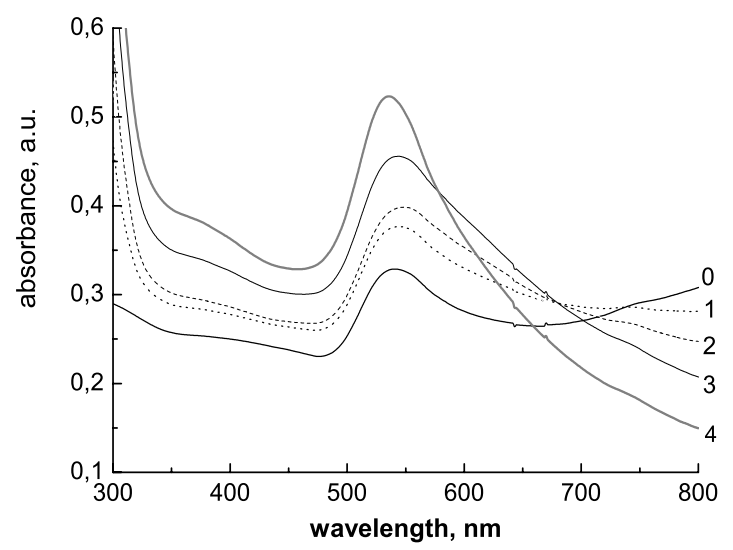

FIG. 5: UV-visible spectrum of a colloidal solution of AuCoNi nanorods in ethanol exposed to radiation of a nanosecond Nd:YAG laser (wavelength:1060 $\mathrm{nm}$ ). Initial colloidal solution (0); after 1 $\min (1), 3 \min (2), 7 \min (3)$ and $12 \min (4)$ of laser exposure. After ref [47].

of a mixture of the monometallic colloidal solutions (figure 6) [48]. Figure 6 presents the plasmon resonance spectra obtained for various values of the exposure time. The initial spectrum presents the plasmon resonance of $\mathrm{Ag}(410 \mathrm{~nm})$ and $\mathrm{Au}(550 \mathrm{~nm})$. Upon irradiation of the mixture, appears first an intermediate phase characterized by an intensity decrease and a shift of the bands of pure Ag and Au towards larger wavelengths. Finally these bands disappear with emergence of a new band at $495 \mathrm{~nm}$ ascribed to an Ag-Au alloy.

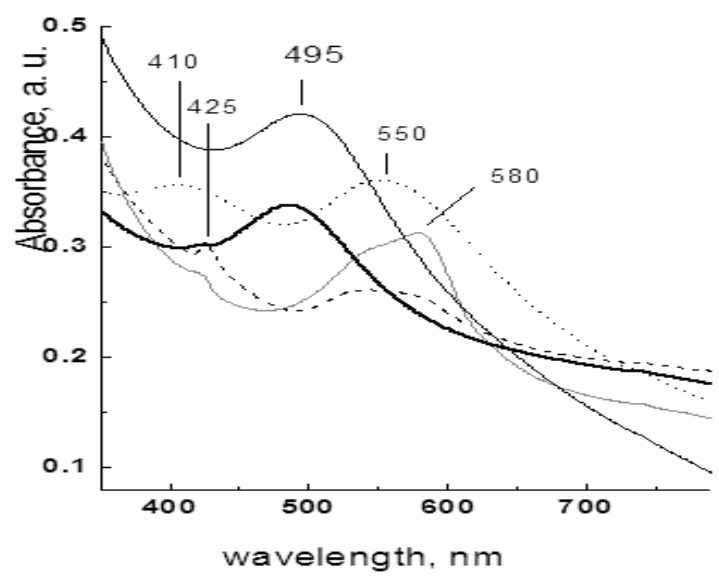

FIG. 6: Evolution of the UV-visible spectrum of a mixture of Ag and Au colloidal solutions in ethanol for various laser irradiation time (Laser fluence: $9.4 \mathrm{~J} / \mathrm{cm}^{2}$ ): initial solution (dotted line), 60 minutes (dashed line), 120 minutes (grey line), 180 minutes (bold solid line), 240 minutes (solid line). After ref [48]

\subsubsection{Laser generation of self-organized nanostructures on solids}

Simultaneously with ejection of nanoparticles from a solid target during laser ablation of a solid, laser radiation is capable of generation of dense arrays of self-organized nanos- 
tructures. Fig. 7 shows an AFM view of an array of such nanostructures, that are formed under ablation of an Ag target in water with a picosecond laser beam. These nanospikes are formed owing to the hydrodynamic instabilities at the interface melt- vapor of the surrounding liquid; the disparities of size arise from the fluctuations of experimental parameters such as laser fluence and local surface roughness.

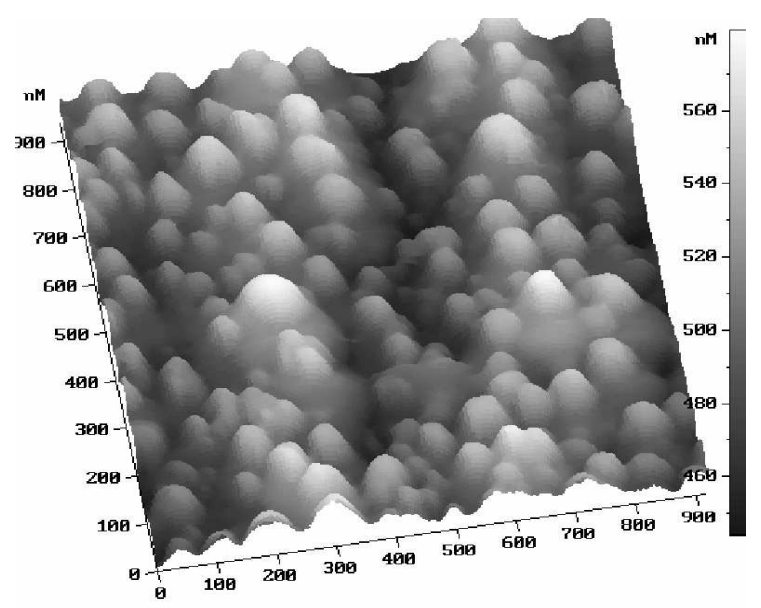

FIG. 7: Atomic Force Microscope (AFM) view of self-organized nanostructures on Ag. Ablation in water, Nd:YAG laser, fluence of $0.4 \mathrm{~J} / \mathrm{cm}^{2}$, pulse duration of $350 \mathrm{ps}$ After ref [49]

The density of these nanostructures on $\mathrm{Ag}$ amounts to $10^{10}$ $\mathrm{cm}^{-2}$ [49]; they show the enhanced Raman scattering of organic molecules adsorbed on them (so called Surface Enhanced Raman Scattering, SERS). The estimated enhancement factor is $10^{5}$ for acridine molecules. Nanostructures can be produced in a similar way on a variety of other metals, e.g., $\mathrm{Ta}, \mathrm{Al}, \mathrm{Ni}$, etc. Estimation of enhancement factor was performed by comparing the Raman signal of organic molecules adsorbed on the nanospikes with that of a solution of the same organic molecule [49]

\section{MULTI-STEP METHODS}

In this case, the synthesis of nanoparticles includes the participation of a solid support. The surface of the support may be considered as a particular template, and the particles as surface-mediated nanoparticles.

\subsection{Fixation of the precursor on the host support, followed by its transformation into the invited phase (oxide or metal)}

Supported palladium catalysts have been extensively studied but hydroxyapatite $\mathrm{Ca}_{5}(\mathrm{OH})\left(\mathrm{PO}_{4}\right)_{3}$ has been much less used as a support. Two examples are presented below.

\subsubsection{PdO/hydroxyapatite catalysts}

The calcium hydroxyapatite is impregnated by a solution of $\mathrm{Pd}\left(\mathrm{NH}_{3}\right)_{4}\left(\mathrm{NO}_{3}\right)_{2}$ before calcination in oxygen at $550^{\circ} \mathrm{C}$.

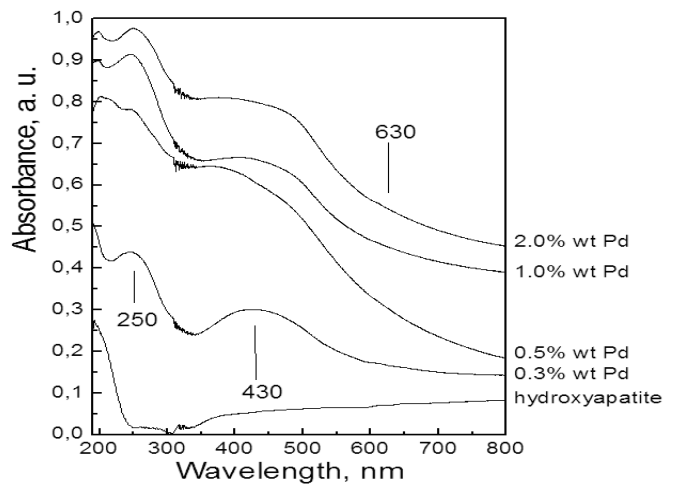

FIG. 8: UV-Visible diffuse reflectance spectra of $\mathrm{Pd}_{\mathrm{x}} \mathrm{O}_{\mathrm{y}}$ supported on hydroxyapatite

At low Pd loading, the $\mathrm{Pd}^{2+}$ ions are isolated and their UVVisible spectrum shows a d-d transition at $430 \mathrm{~nm}$. When increasing the $\mathrm{Pd}$ content, the $\mathrm{Pd}^{2+}$ and oxygen ions form $P d_{\mathrm{x}} O_{\mathrm{y}}$ clusters (figure 8 ) whose absorption edge, determined as in section 3.2. [42, 43], appears at a higher wavelength (about $630 \mathrm{~nm}$ ) than the $\mathrm{d}-\mathrm{d}$ transition of isolated $\mathrm{Pd}^{2+}$ ions and at lower wavelength (higher energy) than bulk PdO, a p-type semiconductor (absorption edge near $1700 \mathrm{~nm}$, not shown). The band at $250 \mathrm{~nm}$ is ascribed to a palladiumoxygen charge transfer.

\subsubsection{Cobalt/Calcium hydroxyapatite systems}

The control of $\mathrm{Co}_{\mathrm{x}} \mathrm{O}_{\mathrm{y}}$ clusters size allows to draw correlations between spectroscopic, magnetic and catalytic properties in the oxidative dehydrogenation of ethane. Two preparation modes were involved [50, 51]: (i) cation exchange which gives isolated paramagnetic $\mathrm{Co}^{2+}$ ions in strong interaction with the support, resistant to oxidation, (ii) impregnation which generates cobalt species weakly bound to the support and more easily oxidized, giving rise to $\mathrm{Co}_{\mathrm{x}} \mathrm{Oy}$ clusters and $\mathrm{Co}_{3} \mathrm{O}_{4}$. Isolated $\mathrm{Co}^{2+}$ ions and cooperating cobalt sites are distinguished by UV-Visible-NIR diffuse reflectance spectroscopy (Figure 9a). Cation exchange leads exclusively to isolated octahedral $\mathrm{Co}^{2+}$, characterized by bands at 520 , 570 and $640 \mathrm{~nm}$ and $1400 \mathrm{~nm}$. Conversely, impregnation generates mainly $\mathrm{Co}_{\mathrm{x}} \mathrm{O}_{\mathrm{y}}$ clusters or $\mathrm{Co}_{3} \mathrm{O}_{4}$, containing tetrahedral $\mathrm{Co}^{2+}$ (640 and 1200-1500 nm) and octahedral (low spin) $\mathrm{Co}^{3+}$ (bands at 430-495 and 725nm).

On the other hand, detailed magnetic measurements (by SQUID), not presented here (see ref $[50,51]$ ) have shown the paramagnetic behaviour of isolated $\mathrm{Co}^{2+}$ whereas antiferromagnetic correlations are developed in $\mathrm{Co}_{\mathrm{x}} \mathrm{O}_{\mathrm{y}}$ clusters (short-distance correlations) or $\mathrm{Co}_{3} \mathrm{O}_{4}$ (long-distance correlations). It must be stressed that a low quantity of $\mathrm{Co}^{2+}$ is exchanged during the impregnation procedure. The nature of Co species (speciation) is summarized on scheme 2 . 
(a)

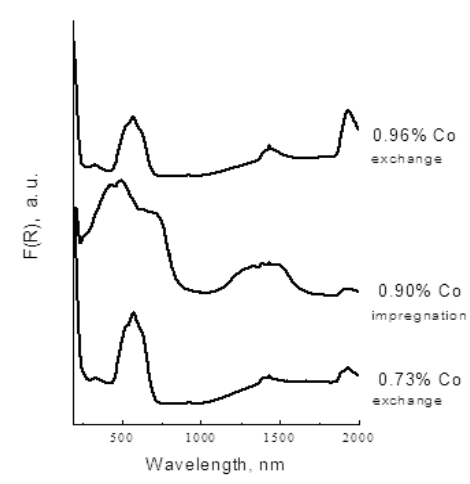

FIG. 9: Cobalt/ Calcium hydroxyapatite catalysts: (a) UV-Visible spectra of samples prepared by cation exchange or by impregnation (b) TEM picture of $\mathrm{Co}_{\mathrm{x}} \mathrm{O}_{\mathrm{y}}$ clusters. After ref [51]

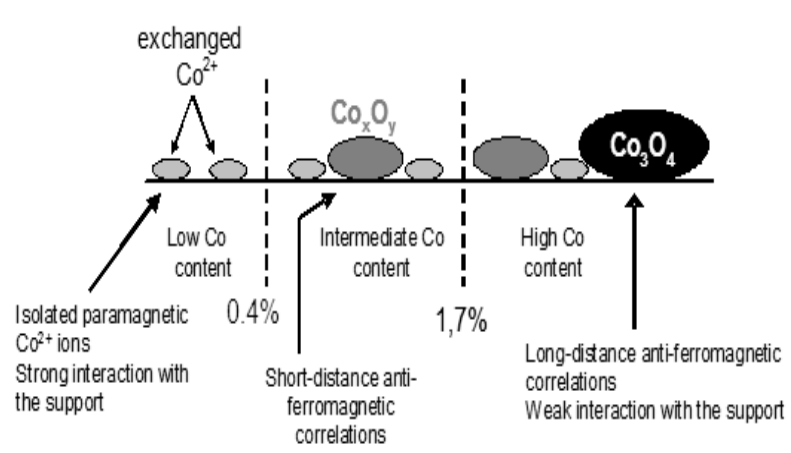

Scheme 2

Finally, the isolated $\mathrm{Co}^{2+}$ ions show much better performance in the oxidative dehydrogenation of ethane $(22 \%$ yield in ethylene at $550^{\circ} \mathrm{C}$ ) than $\mathrm{Co}_{\mathrm{x}} \mathrm{O}_{\mathrm{y}}$ clusters and $\mathrm{Co}_{3} \mathrm{O}_{4}[51]$.

\subsection{Creation of the invited phase in solution before its fixation (immobilization) on the support}

The immobilization of metal particles $(\mathrm{Pd}, \mathrm{Ru})$ on niobia or alumina [52] is performed in two steps. Nanoparticles of $\mathrm{Pd}$ and $\mathrm{Ru}$ in colloidal solutions are first prepared in polyol medium either by steric stabilization by polyvinyl pyrrolidone(PVP) or by electrostatic stabilization. They are redispersed in dichloromethane containing $\gamma$ mercaptopropyltrimethoxysilane ( $\gamma$-MPS) as indicated on figure 10.

The $\gamma$-MPS possess two functional groups: i) a thiol function (A) allowing the interaction with the metallic surface of the nanoparticle and ii) three ethoxy groups which can be readily hydrolyzed for the grafting onto the support (B). Figure 11 shows the micrographs obtained with $\mathrm{Pd}$ and $\mathrm{Ru}$ nanoparticles immobilized on niobia or alumina.

At first sight, one can wonder what is the benefit to use such a sophisticated method. But, this procedure: i) avoids direct metal-support interactions; (ii) offers new possibilities to control the shape, size and structure of colloidal metal par- (a)

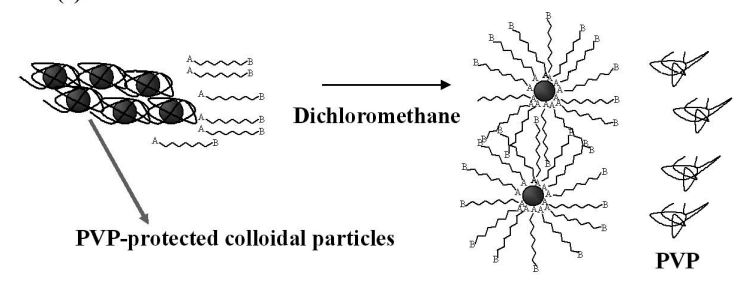

(b)

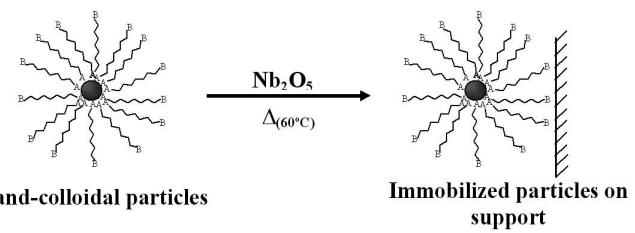

FIG. 10: Preparation of nanoparticles coated with $\gamma$ mercaptopropyltrimethoxysilane (a) and subsequent grafting onto a support (b)

(a)

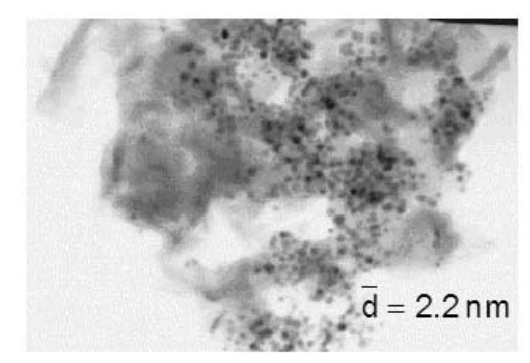

(b)

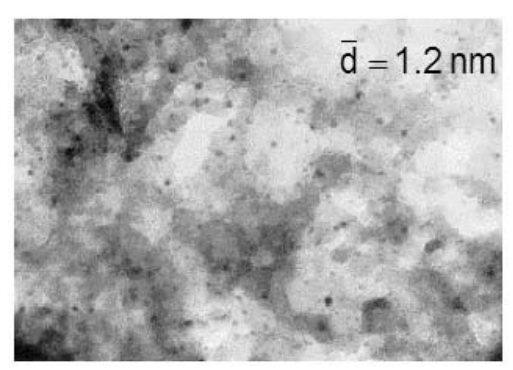

FIG. 11: TEM micrographs of functionalized metal nanoparticles on oxide supports: (a) Pd on niobia and (b) $\mathrm{Ru}$ on alumina

ticles without change upon heterogeneization and (iii) gives higher productivity for obtaining hex-1-ene from hexadiene [52].

\section{CONCLUSION}

Whereas numerous methods allow to generate isotropic or nearly isotropic nanoparticles, the control of size, composition, structure and of anisotropy is much less straightforward. Heterogeneous nucleation promote nanowires and dumbells. 
Laser irradiation of immersed targets and of colloidal solutions allows to produce anisotropic particles or to induce selective fragmentation by tuning the laser wavelength. It produces also alloys nanoparticles from mixtures of monometallic colloidal solutions. Surface mediated methods favor the size control of oxide clusters by choosing the precursor, fixa- tion method and loading, which is an incentive to draw correlations between cluster size and catalytic performances. This variety of methods allows to favor the design of the particular size and shape of nanoparticles associated with specific physical (magnetic, spectroscopic) and chemical (catalytic activity and selectivity) properties.
[1] G. Cao, Nanostructures and Nanomaterials, synthesis, properties and applications, Imperial College Press (2004).

[2] Y. Xia, P. Yang, Y. Sun, Y. Wu, B. Mayers, B. Gates, Y. Yin, F. Kim, H.Yan, Adv. Mater., 15, 353 (2003).

[3] R.C. O'Handley, Modern Magnetic Materials, Principles and Applications, Wiley-Interscience Publication (2000).

[4] F. Fievet in Fine particles : Synthesis, characterization and mechanism of growth. T. Sugimoto ed., Marcel Dekker, Inc. (2000), p 460.

[5] L. Poul, S. Ammar, N. Jouini F. Fievet, F. Villain, J. Sol-Gel Sci. Tech., 26, 261 (2003).

[6] D. Ung, G. Viau, C. Ricolleau, F. Warmont, P. Gredin, F. Fievet, Adv. Mater. 17, 338 (2005).

[7] G.C. Couto, J.K. Klein, W.H. Schreiner, D.H. Mosca, A.J.A. de Oliveira, A.J.G. Zarbin, J. Coll. Interf. Sci. 311, 461 (2007).

[8] D. Li, S. Komameni, J. Amer. Ceram. Soc., 89, 1510 (2006).

[9] Josephus, T. Mtasumoto, H. Takahashi ; D. Kodama, K. Tohji, B. Jeyadevan, J. Solid State Chem. 180, 3008 (2007).

[10] B.K. Park, S. Jeong, D. Kim, J. Moon, S. Lim, J.S. Kim, J. Coll. Interf. Sci., 311, 417 (2007).

[11] F. Chen, Z. Zhong, X.-J. Xu, J. Luo, J. Mater. Sci., 40, 1517 (2005).

[12] M. Tsuji, K. Matsumoto, N. Miyamae, T. Tsuji, X. Zhang, Crystal Growth and Design, 7, 311 (2007).

[13] Y.H. Lee, D.W. Kim, S.I. Shin, S.G. Oh, Mater. Chem. and Phys., 10, 85 (2006).

[14] J.M. Lin, T.L. Lin, U. S. Jeng, Y.J. Zhong, J. Yu, C.T. Yeh, T.Y. Chen, J. Appl. Cristall. 40, s540 (2007).

[15] B. He, Y. Chen, H. Liu, Y. Liu, J. Nanoscience Nanotechnol., 5, 266 (2005).

[16] D. Ung, Y. Soumare, N. Chakroune, G. Viau, M.-J. Vaulay, V. Richard, F. Fievet, Chem. Mater; 19, 2084 (2007).

[17] T. Maurer, F. Ott, G. Chaboussant, Y. Soumare, J.-Y. Piquemal, G. Viau, Appl. Phys. Lett., 91, 172501 (2007).

[18] J.Y. Piquemal, G. Viau, F. Fievet and F. Bozon-Verduraz, Mater. Res. Bull., 38, 389 (2003).

[19] M. Tsuji, K. Matsumoto, N. Miyamae, T. Tsuji, X. Zhang, , Crystal Growth and Design, 7, 311 (2007).

[20] G. Viau, J.Y.Piquemal, M. Esparrica, D. Ung, N. Chakroune, F. Warmont, F. Fievet, Chem. Comm. 17, 2216 (2003).

[21] J. Chatterjee, M. Bettge, Y. Haik, C.J. Chen, J. Magn. Magn. Mater., 293, 303 (2005).

[22] W.X. Chen, J.Y. Lee, Z. Liu, Mater. Lett., 58, 3166 (2004).

[23] C. Liu, X. Wu, T. Klemmer, N. Shukla, X. Yang, D. Weller, A.G. Roy, M. Tanase, D. Laughlin, J. Phys. Chem. B, 108, 6121 (2004).

[24] K. Patel, S. Kapoor, D. P. Dave, T. Mukherjee, Res. Chem. Intermed., 32, 103 (2006).

[25] M. Tsuji, N. Miyamae, S. Lim, K. Kimura, X. Zhang, S. Hikino, M. Nishio, Crystal Growth and Design, 6, 1801 (2006).

[26] C. Feldmann, H.-A. Jungk, Angew. Chem., Int. Ed. 40, 359 (2001).

[27] C. Feldmann, S. Matschulo, S. Ahlert, J. Mater. Sci., 42, 7076 (2007).
[28] A. Subramania, G.V. Kumar, A.R.S. Priya, T. Vasudevan, Nanotechn., 18, 225601/1 (2007).

[29] D.H. Kim, J.W. Kang, T.R. Kim, E.J. Kim, J.S. Im, J. Kim, J. Nanosci. Nanotech., 7, 3954 (2007).

[30] S.H. Ng, D.I. Dos Santos, S.Y. Chew, D. Wexler, J. Wang, S.X. Dou, H.K. Liu, Electrochem. Comm., 9, 915 (2007).

[31] A. Mueller, O. Heim, M. Panneerselvam, M. Willert-Porada, Mater. Res. Bull., 40, 2153 (2005).

[32] Z. Beji, T.B. Chaabane, L.S. Smiri , S. Ammar, F. Fievet, N. Jouini, J.M. Greneche, Physica Status Solidi A, 203, 504 (2006).

[33] W.-W. Wang, Mater. Chem. Phys., 108, 227 (2008).

[34] J. Wan, W. Cai, X. Meng, E. Liu,Chem. Comm., 47, 5004 (2007).

[35] J.-K. Han, H.-Y. Song, F. Saito, B.-T. Lee, Mater. Chem. Phys., 99, 235 (2006).

[36] J.-M. Lee, D.-W. Kim, Y.-H. Lee, S.-G. Oh, Chemistry Letters, 34, 928 (2005).

[37] E.A. Sales, B. Benhamida, V. Caizergues, J.P. Lagier, F.Fievet, F. Bozon-Verduraz, Appl. Catal., 172, 273 (1998)

[38] H. Li, R. Wang, Q. Hong, L. Chen, Z. Zhong, Y. Koltypin, J. Calderon-Moreno, A. Gedanken, Langmuir, 20, 8352 (2004).

[39] R.M. Rioux, H. Song, S. Habas, K. Niesz, J.D. Joefelmeyer, P. Yang, G.A. Somorjai, Topics in Catalysis, 39, 167 (2006).

[40] C.-Y. Lu, M.-Y. Wey, L.-I. Chen, Appl. Catal. A, 325, 163 (2007).

[41] Metal nanoparticles,synthesis, characterization and applications.(D. Feldheim and C.A. Foss, Jr, ed., Marcel Dekker, New York (2002).

[42] R. Brayner, F. Bozon-Verduraz, Phys. Chem. Chem. Phys. 5, 1457 (2003).

[43] R.S. Weber, J. Catal., 151, 470 (1990).

[44] M. S. Sibbald, G. Chumanov, T. M. Cotton, J. Phys. Chem. 100, 4672 (1996).

[45] M.-S.Yeh, Y.-S. Yang, Y.-P. Lee, H.-F. Lee Y.-H. Yeh, C.-S. Yeh, J. Phys.Chem. B, 103, 6851 (1999).

[46] S.I. Dolgaev, A.V. Simakin, V.V. Voronov, G.A. Shafeev, F. Bozon-Verduraz, Appl. Surf. Sci., 186, 546 (2002).

[47] P.V. Kazakevich , A.V. Simakin , G.A. Shafeev , G. Viau ,Y. Soumare, F. Bozon-Verduraz, Appl. Surf. Sci. 253, 7831 (2007).

[48] A.T. Izgaliev, A.V. Simakin, G.A. Shafeev, F. Bozon-Verduraz, Chem. Phys. Lett. 390, 467 (2004).

[49] S. Lau Truong, G. Levi, F. Bozon-Verduraz, A.V. Petrovskaya, A.V. Simakin, G.A. Shafeev, Appl. Surf. Sci., 254, 1236 (2007).

[50] K. El Kabouss, M. Kacimi, M. Ziyad, S. Ammar, F. BozonVerduraz, J. Catal., 16, 226, (2004).

[51] K. El Kabouss, M. Kacimi, M. Ziyad, S. Ammar, A. Ensuque, J.-Y. Piquemal, F. Bozon-Verduraz, J. Mater. Chem. 16, 2453 (2006).

[52] R. Brayner, G. Viau, F. Bozon-Verduraz, J. Mol. Catal; A, 182183, 227 (2002). 